\title{
UAS as flexible and innovative test platform for aircraft configuration and systems testing
}

\author{
Dominique Paul Bergmann ${ }^{1, *}$, Jan Denzel $^{1}$, and Andreas Strohmayer ${ }^{1}$ \\ ${ }^{1}$ University of Stuttgart, Institute of Aircraft Design, 70569 Stuttgart, Germany
}

\begin{abstract}
Today new technologies are available, which can be decisive for the success of future aircraft design. However, the gap between conventional designs and new visions often comes with a high financial risk. This complicates the integration of innovations significantly. The "Flightpath 2050 Europe's Vision for Aviation" asks for new aircraft concepts and configurations to meet future requirements such as emission $(\mathrm{CO} 2, \mathrm{NOx})$, noise and fuel consumption reduction. Scaled UAS are one way for getting new configurations and technologies into flight test while reducing the risk of exploding costs. UAS are cost-efficient test platform systems for two main tasks of future aircraft tests: Testing new configurations and advancing new aircraft systems and technologies from upstream research to TRL5-6. UAS can represent a connection between innovative research and flight demonstration. This paper focuses on the UAS as an innovative test platform and a tool for feasibility demonstration as well as its impact on new technologies and the implementation of innovative concepts. An example of a UAS test platform is given in the paper based on a $33,3 \%$ scale model of the e-Genius. It is developed as flying wind tunnel in order to better understand the effects of configuration changes on flight performance.
\end{abstract}

\section{Introduction}

Since many years Unmanned Aircraft Systems (UAS) play an important role in aviation research. UAS were used especially for development and testing of new aircraft configurations in different research projects. For example, the configuration of a blended wing body for commercial aviation was successfully tested with a scaled unmanned freeflying platform. The collected flight data gave first insights into flight behaviour $[1,2]$ as well as the impact on passenger comfort of such an unknown configuration in flight. Beside CFD analysis and wind tunnel tests, UAS free flight models can be a cost-efficient alternative for the investigation of new aircraft configurations, like shown in different research projects.

\footnotetext{
*Corresponding author: bergmann@ifb.uni-stuttgart.de
} 


\section{Future challenges}

Beside classic requirements for aircraft design new requirements and technologies have to be considered in future aircraft design to meet future political and economic requirements. "Flightpath 2050 - Europe's Vision for Aviation" defines different challenges for future aircraft. One important design driver is to protect the environment [3]:

- Reduce $\mathrm{CO} 2$ and NOx emissions

- Reduce noise emission

- Taxi emission free

To meet these requirements, new technologies are required in aviation, such as for example electric or hybrid-electric powertrains. Especially in the field of emission reduction, these technologies can offer an advantage over conventional propulsion systems. However, the efficient and profitable use of these propulsion systems also means an adaptation of the aircraft configuration.

This technology is already partially available in innovative research concepts, which must be brought to a demonstration in flight. Once tested and proven in flight the technology will have a bigger impact than on a laboratory test level.

These technology changes pose a high risk when it comes to truly redeveloping and certifying such systems for commercial use. A look at the development costs for new aircraft reveals a significant increase [4] in development costs per seat. This cost increase is reinforced when new technologies are used, such as in the A350 or B787 [4]. This is one of the main reasons why todays aircraft configurations rely on well-known configuration types and technologies. Novel technologies enter commercial design level only very slowly.

To be able to implement the given goals as quickly and efficiently as possible and to minimize the financial risk for the manufacturers, the challenge will be to create an economical way to bring up the already developed technologies to the appropriate technology readiness level (TRL), where they get interesting for commercialisation due to a significantly lower financial risk.

Beside the reduction of financial risk, development time must be reduced. Today the development of new technologies (flying components) for aviation takes around 20 years [4]. To be innovative and competitive in future aircraft design the development time of single technologies must be accelerated. Only a fast availability of different new technologies, which are close to the point of commercialisation, can be used for a novel and innovative aircraft design to solve future challenges.

\subsection{Accelerate technology readiness}

To accelerate the TRL of new technologies and concepts UAS can be a handsome tool for the future, promoting an aircraft design, which will be innovative and competitive on the international market with novel concepts and technologies. UAS should not replace manned flight test. However, they can be an extending tool, providing a link between upstream research and technology demonstration. In this way UAS as test bed for technology investigation and demonstration can be an additional tool beside classic analytic design method and CFD calculation.

Because flight campaigns with unmanned aircraft in a restricted test area can be less restrictive than manned flight testing, new technologies can be faster integrated and earlier tested in flight. This fast technology demonstration in relevant environment brings some benefits in the development process. One point is that in this way concept issues can be identified in early design phases, reducing cost for changes. Another reason is that potential regulatory barriers can also be identified and properly addressed at an early stage. 
This allows reducing the financial risk for commercializing projects of innovative technologies by identifying potential development risks and to exclude them.

Feasibility and impact of technologies can be demonstrated at early development stages. This makes them more descriptive and predictable to bring them from science to business.

\subsection{Vision of UAS test bed}

The idea of scaled down free flight test models is not new. Since 1920 NASA is using models for scale testing of aircraft [5]. In the early times of UAS in flight test the platforms were for example dropped from a helicopter. Observed by on-board cameras, the uncontrolled glide slope back to the ground was recorded. Later, the systems became more complex and effective.

In the following time, UAS were used as a test bed for several disciplines. As examples for the latest projects, there should be mentioned the $\mathrm{x} 48$ program and, at the German side, the K2020 project with its VEALII (Fig. 1) demonstrator as well as the EU founded NACRE project [Fig. 2].

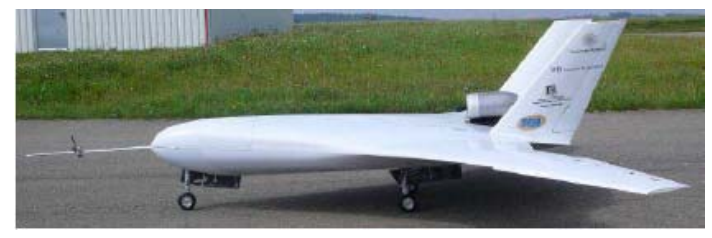

Fig. 1. VelaII Demonstrator

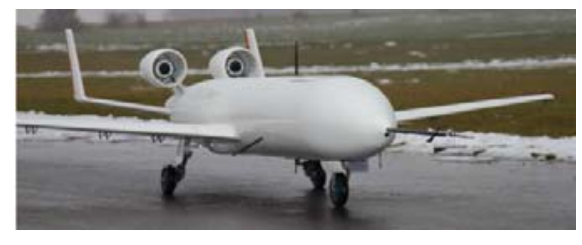

Fig. 2. IEP / NACRE Project

These more recent projects were used for flight dynamics and noise assessment purposes. But also, general questions as the scalability of certain aerodynamic effects can be an output. This would include for example the integration of distributed propulsion or a scaled down hybrid electric powertrain. As a requirement for the validation of the flight test results, a comparability of these data with the full-scale aircraft must be given.

\section{Technology test bed e-Genius-Mod}

The free-flight platform e-Genius-Mod [Fig. 3] is a 33.3\% scale model of the e-Genius, a full-electric two persons touring motor glider. The e-Genius-Mod is scaled in compliance with the similarity conditions of Froude number and Reynolds number as a free flight model [2].

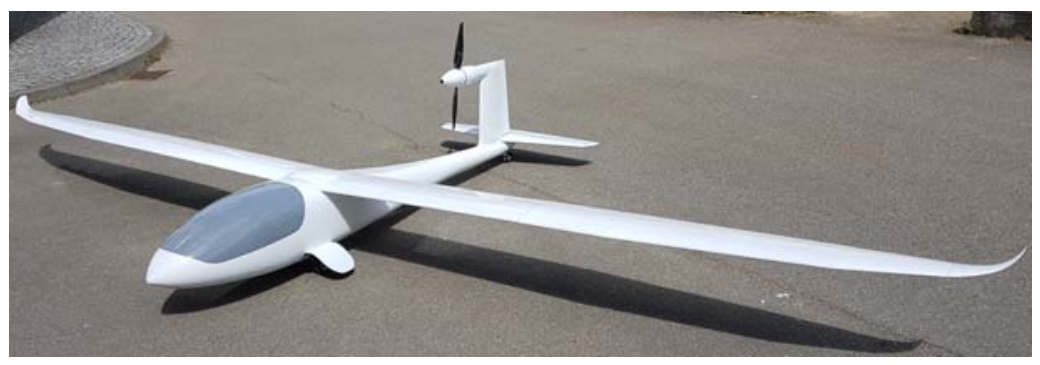

Fig. 3. e-Genius-Mod 33.3\% free-flight model

The full-scale e-Genius is a manned technology test aircraft at the Institute of Aircraft Design, University of Stuttgart. e-Genius [Fig. 4] is built to demonstrate the 
competitiveness of modern electrical propulsion over conventional propulsion systems in aviation. It has a wingspan of $16.9 \mathrm{~m}$ and a MTOM of $950 \mathrm{~kg}$. The electrical engine allows a max. range of more than $400 \mathrm{~km}$.

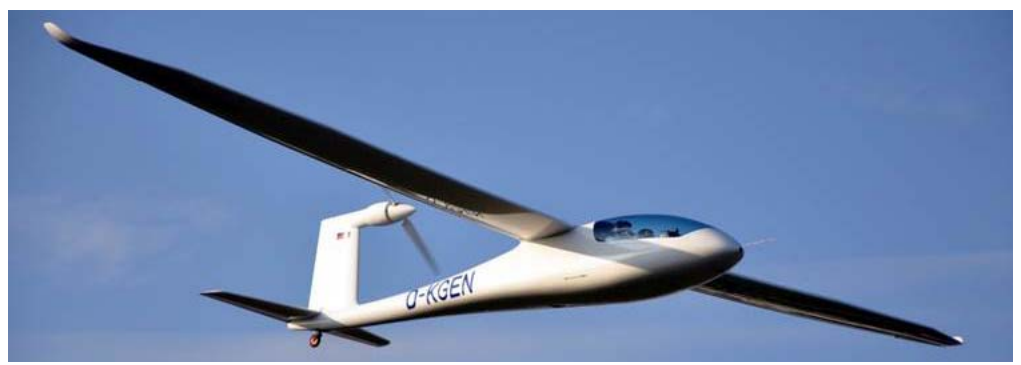

Fig. 4. e-Genius [University of Stuttgart, Institute of Aircraft Design]

The model is prepared as a technology test bed to demonstrate new technologies for future aircraft design in relevant environment. The UAS test bed will be used for academic and innovative research projects to demonstrate new technologies up to TRL6. The design of the test bed is primarily prepared for the investigation of new aircraft configuration solutions for distributed electric propulsion systems.

The test bed e-Genius-Mod will be an extension of the full-scale aircraft for further investigation of electrical flight. Electrical propulsion systems give new possibilities of propulsion integration to aircraft design. To investigate and demonstrate these innovations, a flexible test bed like the unmanned scale model is required. The demonstration of innovative concepts like distributed propulsion on a manned aircraft is expensive and time intensive and not useful for research with open results. With its modular airframe design the e-Genius-Mod is the basis for an efficient and systematic research of the various effects of distributed propulsion.

Once the similarity requirements between the scale model and the full scale aircraft are identified, the model is a pre-test bed for the full scale. Results like performance improvements can be collected and the promising concept is identifiable for integration at the full scale.

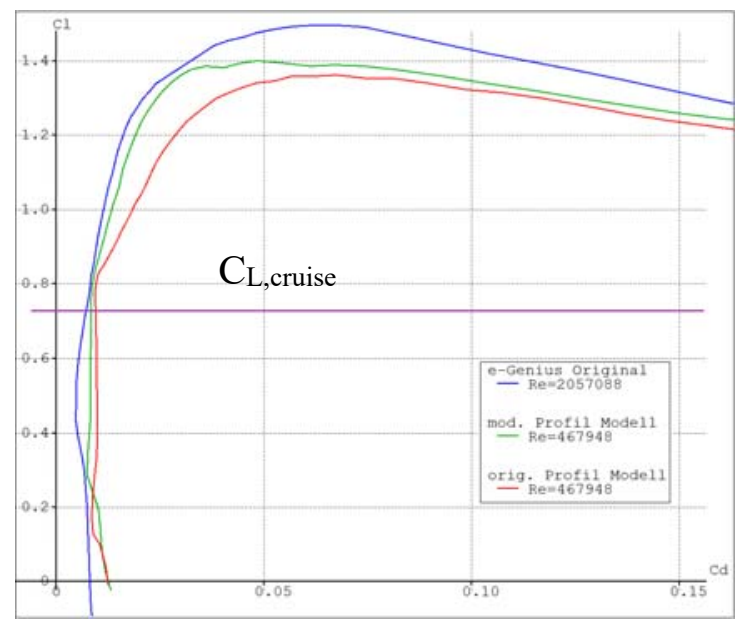

Fig. 5. Drag to Lift - scaled profile vs. full-scale model [6] 
The model is prepared in respect to the similarity between scale and full-scale aircraft to investigate cruise flight. As the wing profile was not able to allow similarity adherence by the Froude number the profile was modified. Design target for changing the profile geometry was to get an equal lift to drag polar [Fig. 5] and lift to angle of attack polar. The modification aims to realize similarity under cruise flight conditions, as the focus of the investigation is on cruise flight.

\subsection{Overview e-Genius-Mod}

Table 1 Technical Data e-Genius-Mod

\begin{tabular}{|l|l|}
\hline Wingspan & $5.62 \mathrm{~m}$ \\
\hline Length & $2,7 \mathrm{~m}$ \\
\hline MTOM & $40 \mathrm{~kg}$ \\
\hline Propulsion & $\begin{array}{l}5 \mathrm{~kW} \text { electric motor } \\
\text { Propeller RASA 24x12 }\end{array}$ \\
\hline Battery & $1-2 \mathrm{P} 12 \mathrm{~S} 21000 \mathrm{mAh}$ \\
\hline $\begin{array}{l}\text { Estimated flight } \\
\text { time }\end{array}$ & $30-60 \mathrm{~min}$ \\
\hline Autopilot & Pixhawk 4 \\
\hline
\end{tabular}

\section{Flexible Airframe Configuration}

To have a flexible test bed the model is divided in two fuselage segments and eight wing segments [Fig. 6]. The modular design of the model gives freedom to the user to change the configuration without building a completely new airframe. The single segments are pluggable to each other. The interface between the segments is designed to transmit loads. Also, they have the connecting points for power transmission and data bus.

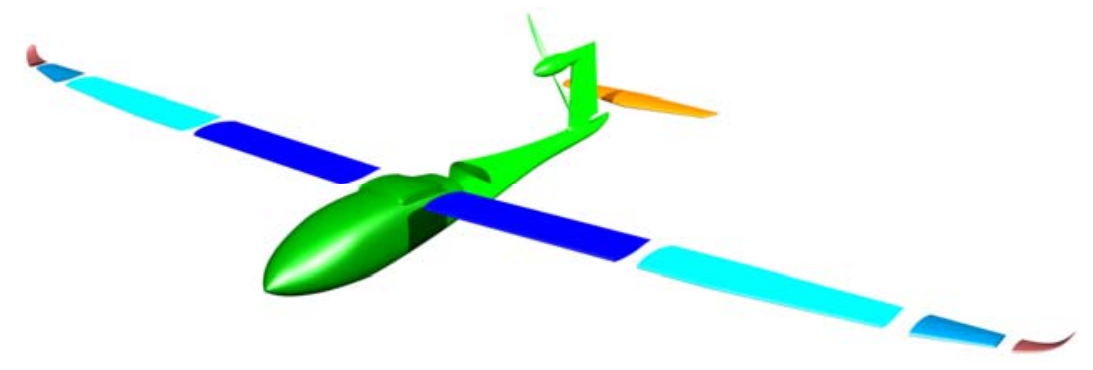

Fig. 6. Segment overview e-Genius-Mod 


\section{Systems Design}

In respect to safety conditions, the systems design is realized with redundancy where possible.

The core of the flight management system is built around a Pixhawk 4 autopilot. Beside the $\mathrm{RC}$-receiver all data in and output is realized with to buses, which are connected to every single segment of the e-Genius-Mod. In this way all system components can be directly connected to the autopilot. So, each single segment can be prepared ready to fly and can be tested, before being integrated into the aircraft, without realizing and checking a new wiring in the aircraft.

The actuators of the control surfaces are always connected to one of the buses. To have still a limited maneuverable aircraft, even in case one bus is interrupted, the actuators are divided up on the remaining two buses. Limited by the data rate of the bus new actuators, sensors, etc. can be added easily to the test platform. With a Powerbox a redundant power supply for the flight management system and the actuators is realized. Even more the Powerbox allows connecting two radio controllers to have a better radio coverage.

\section{Variable Pitch Propeller}

In order to model several flight conditions in a realistic way with respect to the propulsion system, the scaled down e-Genius-Mod is fitted with a constant speed propeller system. Hereby it is possible to operate the model in its optimal operating points, for example during climb or cruise [Fig. 7]. A variable pitch propeller permits to operate the propulsion components in the point of their maximum point of efficiency.

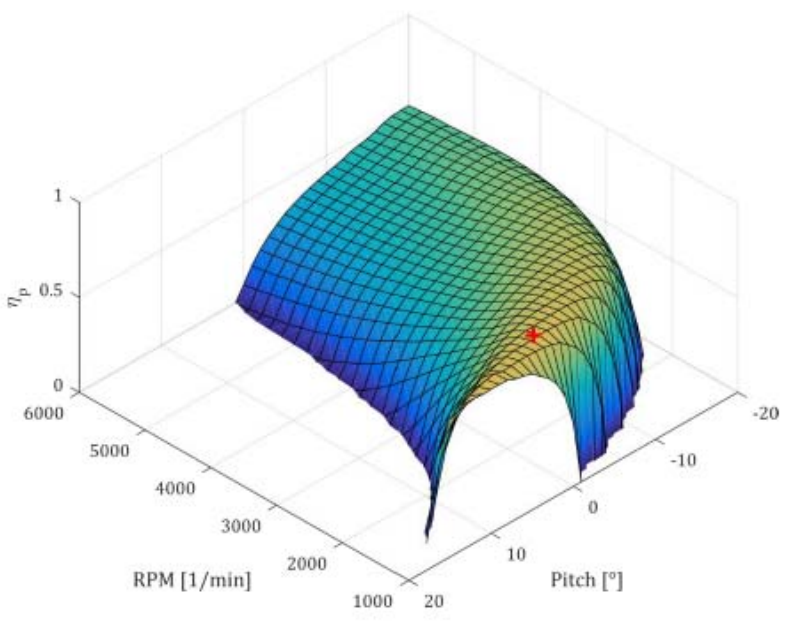

Fig. 7. Propeller efficiency at $17 \mathrm{~m} / \mathrm{s}$ TAS [7]

\section{Flying Wind tunnel e-Genius-Mod}

To investigate new configurations and technologies in flight, the free flight model eGenius-Mod is equipped as flying wind tunnel. Main module of the measurement system is the IMU which is also required for the flight management system. The IMU supplies the log system with data of flight attitude (orientation angle, acceleration, rotation rate). Angle of attack and side slip are measured with an air data boom installed at the nose of the aircraft to get an undisturbed air flow. Also integrated at the air data boom is a pitot probe and a temperature sensor. A GPS is integrated for recording of position and flight track. For 
the investigation of flight mechanics the actuators are able to give a feedback of measured position to calculate the actual control surfaces deflection.

\subsection{Application example - Investigation of a wing tip propulsion system}

As stated before, the flexibility of the UAS test bed and its modular design can be perfectly used as investigation and demonstration platform for distributed propulsion systems. In a first step a wing tip propeller will be investigated in the project ELFLEAN (Electric wing tip propulsion system for the development of energy-efficient and noise reduced airplanes), supported by Federal Ministry for Economic Affairs and Energy on the basis of a decision by the German Bundestag.

One point of the project is to test the wing tip propulsion system in flight on the UAS test bed e-Genius-Mod. For a more efficient investigation of the effects of wing tip propulsion, the aspect ratio of the UAS shall be reduced to increase induced drag.

Through the modular concept these requirements can easily be fulfilled. As shown in Fig. 8 the outer segments of the wing can be disconnected to have a ready to fly reference configuration for the investigation.

Also, the connection of the wing tip propulsion system can be realized [Fig. 9] with just a new lay-up tool for the pods of the system. An interface to connect the pods to the structure and the flight management system is already available on the shorted end of the wing.

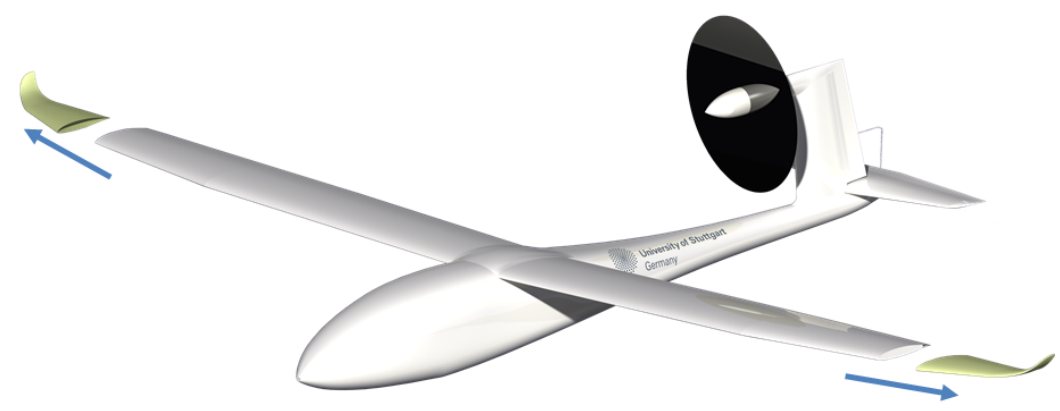

Fig. 8. e-Genius-Mod with disconnecting wing tips to reduced aspect ratio

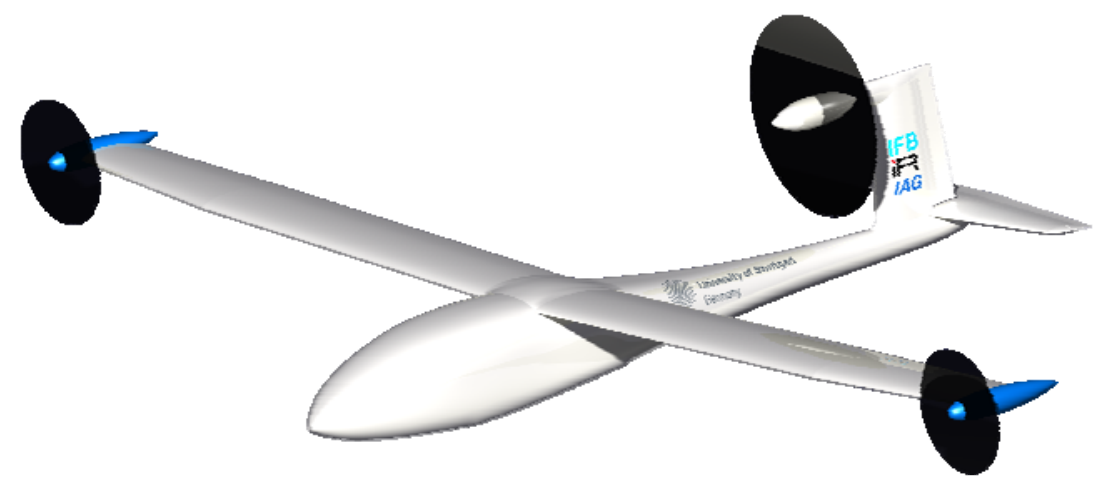

Fig. 9. e-Genius-Mod with integrated Wing tip propulsion system 


\section{Outlook}

The UAS test platform e-Genius-Mod currently is being used to test and validate various effects of distributed propulsion. Beyond this, it is planned to use the platform for all kinds of technologies, such as for example structural concepts, acoustical analysis, flight guidance and navigation or data transmission technologies. This will further demonstrate the value of modular and versatile UAS platforms for the early, safe and cost effective flight testing of innovative technologies and concepts.

\section{References}

1. K. Kittmann, Entwicklung einer modularen Messplattform zur Analyse des Potenzials von Freiflugmessungen, Dissertation, University of Stuttgart, Institute of Aircraft Design (2013)

2. C. H. Wolowicz, J. S. Bowman, Jr., W.P. Gilbert, Similitude Requirements and Scaling Relationships as Applied to Model Testing, NASA Technical Paper 1435, (1979)

3. European Commission, Flightpath 2050 Europe's Vision for Aviation, Report of the High Level Group on Aviation Research (2011)

4. IATA Technology Roadmap 2013, $4^{\text {th }}$ Edition (2013)

5. J. R. Chambers, Modeling Flight, The Role of Scaled Free-Flight Models in Support of NASA`s Aerospace Programs, NASA

6. A. Baden, Entwurf eines Freiflugmodells des E-Motorseglers e-Genius unter Berücksichtigung der aerodynamischen Vergleichbarkeit, Bachelorthesis, University of Stuttgart, Institute of Aircraft Design (2016)

7. L. Kugler, Analysis and characterization of the variable pitch propeller for the Scaleddown e-Genius, Bachelor thesis, University of Stuttgart, Institute of Aircraft Design (2018) 